\title{
Infection of Anopheles gambiae mosquitoes with entomopathogenic fungi: effect of host age and blood-feeding status
}

\author{
Ladslaus L. Mnyone • Matthew J. Kirby • Monica W. Mpingwa • \\ Dickson W. Lwetoijera • Bart G. J. Knols • Willem Takken • \\ Constantianus J. M. Koenraadt • Tanya L. Russell
}

Received: 12 July 2010 / Accepted: 10 September 2010 / Published online: 25 September 2010

(C) The Author(s) 2010. This article is published with open access at Springerlink.com

\begin{abstract}
Physiological characteristics of insects can influence their susceptibility to fungal infection of which age and nutritional status are among the most important. An understanding of host-pathogen interaction with respect to these physiological characteristics of the host is essential if we are to develop fungal formulations capable of reducing malaria transmission under field conditions. Here, two independent bioassays were conducted to study the effect of age and blood-feeding status on fungal infection and
\end{abstract}

L. L. Mnyone $(\bowtie) \cdot$ M. J. Kirby $\cdot$ M. W. Mpingwa $\cdot$

D. W. Lwetoijera $\cdot$ T. L. Russell

Biomedical and Environmental Group, Ifakara Health Institute, P.O. Box 53, Off Mlabani Passage, Ifakara, Tanzania e-mail: 1laurent@ihi.or.tz

L. L. Mnyone • M. J. Kirby • W. Takken • C. J. M. Koenraadt Laboratory of Entomology,

Wageningen University and Research Centre,

P.O. Box 8031, 6700 EH Wageningen, The Netherlands

L. L. Mnyone

Pest Management Centre, Sokoine University of Agriculture,

P.O. Box 3110, Morogoro, Tanzania

B. G. J. Knols

Division of Infectious Diseases,

Tropical Medicine and AIDS Academic Medical Center,

F4-217, Meibergdreef 9,

1105 AZ Amsterdam, The Netherlands

T. L. Russell

The University of Queensland, School of Population Health, Australian Centre for Tropical and International Health, Brisbane 4006, Australia

T. L. Russell

Vector Group, Liverpool School of Tropical Medicine,

Liverpool L3 5QA, UK survival of Anopheles gambiae s.s. Giles. Mosquitoes were exposed to $2 \times 10^{10}$ conidia $\mathrm{m}^{-2}$ of oil-formulated Metarhizium anisopliae ICIPE-30 and of Beauveria bassiana I93-825, respectively, and their survival was monitored daily. Three age groups of mosquitoes were exposed, 2-4, 5-8, and 9-12 days since emergence. Five groups of different feeding status were exposed: non-blood-fed, 3,12 , 36 , and $72 \mathrm{~h}$ post-blood feeding. Fungal infection reduced the survival of mosquitoes regardless of their age and blood-feeding status. Although older mosquitoes died relatively earlier than younger ones, age did not tend to affect mosquito susceptibility to fungal infection. Nonblood-fed mosquitoes were more susceptible to fungus infection compared to all categories of blood-fed mosquitoes, except for those exposed to B. bassiana $72 \mathrm{~h}$ postblood feeding. In conclusion, formulations of $M$. anisopliae and $B$. bassiana can equally affect mosquitoes of different age classes, with them being relatively more susceptible to fungus infection when non-blood-fed.

\section{Introduction}

Recent studies increasingly demonstrate the potential for controlling malaria vectors by using entomopathogenic fungi (Scholte et al. 2005; Blanford et al. 2005; Farenhorst et al. 2008; Mnyone et al. 2009). These fungi do not cause instant mortality but cause sublethal and late-life lethal effects on different stages of the mosquito life cycle. Due to such properties, fungi can potentially be used as "evolutionproof" agents and overcome mosquito resistance unlike the currently deployed fast-acting chemical insecticides (Ffrench-Constant 2005; Koella et al. 2009; Read et al. 2009). As part of an integrated strategy, fungi could 
respond to, or avert emergence of serious levels of insecticide resistance. For instance, recent laboratory studies by Farenhorst et al. (2009) recorded similar susceptibility to fungal infection between insecticide-resistant and nonresistant colonies of Anopheles mosquitoes. Furthermore, theoretical modeling suggests the existence of a synergistic interaction between fungal biopesticides and insecticide treated bed nets even in scenarios of high malaria intensity and widespread insecticide resistance (Hancock 2009). This suggestion was validated by a recent study in Benin, where there was a strong interaction of the insecticide permethrin and the fungi Metarhizium anisopliae or Beauveria bassiana (Farenhorst et al. personal communication) on mosquito survival.

Under field conditions, entomopathogenic fungi target mosquitoes of different physiological characteristics, which may influence their overall effectiveness as biocontrol agents. Host species, age, developmental stage, sex, and nutritional status have frequently been reported to affect insect susceptibility to fungal infection (Feng et al. 1985; Maniania and Odulaja 1998; Dimbi et al. 2003). Host age and feeding status are among the most important physiological characteristics. A critical understanding of the hostpathogen interaction with respect to these host physiological characteristics, therefore, is essential for the development of formulations capable of suppressing malaria transmission under real life conditions.

Mosquito populations are known to experience senescence (Harrington et al. 2001; Okech et al. 2003; Styer et al. 2007). As mosquitoes age, adverse changes to major life-history parameters have been recorded, including differences in mortality, flight capacity, immune function, salivary gland function, and cuticular hydrocarbon composition (Rowley and Graham 1968; Nayar and Sauerman 1973; Beckett 1990; Chen et al. 1990; Brei et al. 2004; Hugo et al. 2006). The susceptibility of mosquitoes to fungal infection could be affected when (1) the insect cuticle weakens with age, thereby facilitating more successful fungal penetration; and (2) a lowered immune response allows the fungus to rapidly propagate inside the host. Recent research has demonstrated greater susceptibility of older (17-21 days old) than younger (3-7 days old) Anopheles stephensi mosquitoes to three species of entomopathogenic fungi (Stevenson J., unpublished data). This age composition, however, may not be representative of that of mosquitoes under realistic field conditions, where only a small proportion of mosquitoes may survive for 21 days or longer (Gillies and Wilkes 1965). More importantly, the wild vector community is normally composed of various species of mosquitoes, and this may dictate their survival and aging effect trends. As such, knowledge about species-specific aging effects in younger mosquitoes compared between a relatively narrow age range will be of added value. Higher susceptibility in older than younger individuals has also been reported in studies of other insects. The susceptibility of tsetse flies to $M$. anisopliae was greater among older than younger individuals (Maniania and Odulaja 1998). Similar phenomena have been observed with regard to insecticides. The mean knockdown times of A. stephensi and Anopheles gambiae mosquitoes exposed to pyrethroids were significantly shorter if they were 10 days old as compared to those of newly emerged ones (Hodjati and Curtis 1999). Nevertheless, contrasting reports, where greater susceptibility has been recorded in younger than older insects, also exist (Mullens 1985; Dimbi et al. 2003).

Nutritional differences between non-blood-fed and bloodfed mosquitoes may also affect the efficacy of a fungal-based intervention. Various studies have recorded contradicting effects of blood feeding on mosquito longevity. One hypothesis is that mosquitoes which are fed on blood alone, without access to sugar, will have lower survival, possibly because nutrients are diverted for egg production (Okech et al. 2003). Alternately, other experiments have recorded that blood feeding can actually increase mosquito survival when compared with mosquitoes fed only on sugar (Scott et al. 1993; Scott et al. 1997). The nutritional benefits of blood feeding could alter the efficacy of fungal infections due to changes in the host's ability to activate an immune response or, conversely, alter the level of nutrients available for pathogen propagation. Rhodnius prolixus bugs that were fed on blood showed a higher immune response to Enterobacter cloacae infection compared to $R$. prolixus fed on plasma (Feder et al. 1997). A similar susceptibility trend was observed between freshly blood-fed and non-blood-fed $A$. gambiae (G3 strain, originating from The Gambia) mosquitoes (J. Stevenson, unpublished data). In that study mosquitoes were fed directly on rats.

Under realistic field situations, mosquito vectors of different age and blood-feeding status may be encountered. An understanding of host-pathogen interaction with respect to mosquito age and blood-feeding status, therefore, is essential if we are to develop fungal formulations capable of reducing malaria transmission. This study was designed to examine if efficacy of $M$. anisopliae ICIPE-30 and $B$. bassiana 193-825 varied with mosquito age and human blood feeding. This information will be essential for designing delivery mechanisms to expose the most susceptible portion of the mosquito population to fungal infection.

\section{Materials and methods}

\section{Mosquitoes}

Mosquitoes originated from a colony of $A$. gambiae s.s. established from Njage village, Tanzania in 1996 and 
maintained at the Ifakara Health Institute. Larvae and adults were reared using procedures described by Huho et al. (2007). Bioassays were conducted using fed and unfed adult female mosquitoes.

Fungal isolates, formulation, and application

Two fungal isolates were used in this study: $M$. anisopliae var. anisopliae ICIPE-30, isolated in 1989 from the maize stalk borer, Busseola fusca (Lepidoptera, Noctuidae) in Western Kenya, and B. bassiana I93-825 (IMI 391510), isolated from a chrysomelid beetle (Coleoptera) in the USA. Before each experiment, viability of conidia (i.e., percent germination on Sabouraud Dextrose Agar) was confirmed to be $>85 \%$.

Conidia were formulated in Enerpar, a highly refined mineral oil (Enerpar M002 ${ }^{\circledR}$, BP Southern Africa Ltd.). Stock and working conidia suspensions were prepared using procedures described by Mnyone et al. (2009). In all bioassays, a concentration of $2 \times 10^{10}$ conidia $\mathrm{m}^{-2}$ was used. Mosquitoes were exposed to conidia applied to sheets of A4 printing paper within plastic exposure tubes, closed with netting also treated with conidia. The paper and netting were treated using a hand-held pressure sprayer (Minijet ${ }^{\circledR}$, SATA, Germany) operating at a constant pressure of two bars. The nozzle of the spray gun was held $50 \mathrm{~cm}$ away from, and at a right angle to, the application surface. A working solution of $23 \mathrm{ml}$ containing $2 \times 10^{10}$ conidia was applied to a $1-\mathrm{m}^{2}$ area. Treated surfaces were left to dry for $24 \mathrm{~h}$.

\section{Bioassay procedures}

Thirty to forty adult $A$. gambiae s.s. mosquitoes were introduced into the fungal exposure tube $(8.2 \mathrm{~cm}$ diameter $\times$ $12.5 \mathrm{~cm}$ height) and held for $6 \mathrm{~h}$ after which they were transferred to separate untreated cages $(9 \times 9 \times 9 \mathrm{~cm})$ and maintained at $26-27^{\circ} \mathrm{C}$ and $85-95 \%$ relative humidity (RH) with access to $9 \%$ glucose solution ad libitum. Based on earlier observations, $6 \mathrm{~h}$ was considered an appropriate exposure period (Mnyone et al. 2009). Mosquito survival was determined by recording mortality in each holding cage for a maximum of 28 days. Cadavers were collected daily, put onto moist filter paper in Petri dishes, sealed with Parafilm and incubated at $26-27^{\circ} \mathrm{C}$ and $85-95 \% \mathrm{RH}$ for $3-$ 4 days. After that, they were then examined for evidence of fungal sporulation. Similar bioassay procedures were followed for 30-40 mosquitoes in control groups, except that they were exposed to untreated surfaces. During all of the bioassays, six independent replicates were used for each experimental factor. Two different bioassays were conducted to study the effect of age and blood feeding on infection and survival of $A$. gambiae s.s.
Bioassay 1: effect of mosquito age on infection and survival

Three different age groups of female mosquitoes were exposed to both fungal isolates: (1) 2-4 days, (2) 5-8 days, and (3) 9-12 days postemergence.

\section{Bioassay 2: effect of mosquito blood feeding on infection and survival}

Five groups with differing blood-feeding status were exposed to both fungal isolates: (1) non-fed, (2-5) 3, 12, 36 , or $72 \mathrm{~h}$ post-blood feeding. Mosquitoes were starved of glucose for $6 \mathrm{~h}$ before blood feeding. For blood feeding, a volunteer placed a bare forearm inside the cage and allowed mosquitoes to feed for $10 \mathrm{~min}$. After blood feeding, all unfed and partially fed mosquitoes were aspirated out of the cage leaving only fully engorged mosquitoes. Blood feeding was scheduled so that when the mosquito groups were exposed to the fungus they were in the age range of 3-6 days.

\section{Data analysis}

Mosquito survival data were analyzed using Cox regression to determine the relative risk of dying [hazard ratios (HR)] for the specific treatment group compared with the baseline group. The explanatory factors included in the analysis were fungal treatment, mosquito age, and blood feeding status, as required. Hazard ratios of each mosquito category and its respective control were generated in independent models to observe if confidence intervals (CI) were suggestive of any interaction between fungus-related mortality and age or blood meal. Non-blood-fed mosquito data was run against each of the four categories of bloodfed mosquitoes generating four independent models to confirm interaction between fungus-related mortality and a blood meal. Kaplan-Meier pairwise method was used to obtain median survival times (MST) for treated and untreated group of mosquitoes. The Bonferroni method was employed to compensate for multiple comparisons. SPSS version 17 was used.

\section{Results}

Bioassay 1: effect of mosquito age on infection and survival

Overall, the survival of all three different age groups of mosquitoes was reduced relative to their control counterparts when exposed to both $M$. anisopliae and B. bassiana (Table 1). The daily risk of dying was over twofold greater in mosquitoes exposed to $M$. anisopliae relative to controls $[\mathrm{HR}=2.26(95 \% \mathrm{CI}=1.86-2.74), p<0.001]$, whereas the 
Table 1 Median survival times (MST $\pm \mathrm{SE}$ ) of different age groups (2-4, 5-8, and 9-12 days old) of A. gambiae s.s. exposed to $M$. anisopliae ICIPE-30 and B. bassiana I93-825

\begin{tabular}{lllll}
\hline Fungus species & \multicolumn{2}{l}{ MST \pm SE (days) } & \\
\cline { 2 - 5 } & Age (days) & Control & Treatment & $P$ value \\
\hline M. anisopliae & $2-4$ & $15 \pm 0.51$ & $8 \pm 0.51$ & $<0.001$ \\
ICIPE-30 & $5-8$ & $14 \pm 0.39$ & $7 \pm 0.39$ & $<0.001$ \\
& $9-12$ & $11 \pm 0.25$ & $5 \pm 0.25$ & $<0.001$ \\
B. bassiana & $2-4$ & $15 \pm 0.51$ & $7 \pm 0.28$ & $<0.001$ \\
I93-825 & $5-8$ & $14 \pm 0.39$ & $6 \pm 0.22$ & $<0.001$ \\
& $9-12$ & $11 \pm 0.25$ & $6 \pm 0.28$ & $<0.001$ \\
& & & & \\
\hline
\end{tabular}

daily risk of dying was over threefold greater in mosquitoes exposed to $B$. bassiana relative to controls $[\mathrm{HR}=3.46(95 \%$ $\mathrm{CI}=2.85-4.19), p<0.001]$.

Irrespective of fungus infection, the age of mosquitoes affected the rate at which they were dying, with older mosquitoes dying relatively earlier than younger ones $(M$. anisopliae: Wald $=75.54 ; \mathrm{df}=2 ; p<0.001, B$. bassiana: Wald $=76.16$; $\mathrm{df}=2 ; p<0.001$ ). For $M$ anisopliae, the risk of dying was greater in 9-12-day-old mosquitoes relative to $2-4$ days old $[\mathrm{RH}=1.52(95 \% \mathrm{CI}=1.27-1.82), p<0.001]$ and 5-8-day-old $[\mathrm{RH}=1.25$ (95\% CI=1.04-1.50), $p<$ 0.001] mosquitoes. Similarly, for B. bassiana, the risk of dying was greater in 9-12-day-old mosquitoes relative to 2-4-day-old $[\mathrm{RH}=1.51 \quad(95 \% \mathrm{CI}=1.26-1.81), p<0.001]$, and 5-8-day-old $[\mathrm{RH}=1.51 \quad(95 \% \mathrm{CI}=1.26-1.83), p<$ $0.001]$ mosquitoes. For both fungal species, the latter two age groups of mosquitoes had a similar risk of dying $[\mathrm{RH}=$ $1.22(95 \% \mathrm{CI}=1.01-1.47), p=0.06]$. There was no overall significant interaction, however, between age and rate at which fungus-infected mosquitoes were dying (M. anisopliae: Wald $=1.76 ; \mathrm{df}=2 ; p=0.42$, B. bassiana: Wald $=1.60$; $\mathrm{df}=2 ; p=0.21$ ).

Bioassay 2: Effect of mosquito blood feeding on infection and survival

The survival of all fungus-infected mosquitoes was reduced compared to their control counterparts when mosquitoes were non-fed or $3,12,36$, or $72 \mathrm{~h}$ post-blood feeding (Table 2). The daily risk of dying was over twofold greater in mosquitoes exposed to $M$. anisopliae $[\mathrm{HR}=2.75(95 \%$ $\mathrm{CI}=2.27-3.33), p<0.001]$ and $B$. bassiana $[\mathrm{HR}=2.28(95 \%$ $\mathrm{CI}=1.87-2.78), p<0.001]$ relative to controls.

A blood meal significantly affected the rate at which mosquitoes died, and overall, blood-fed mosquitoes had a lower risk of dying relative to unfed ones ( $M$. anisopliae: Wald $=95.39 ; \quad \mathrm{df}=4 ; p<0.001, B$. bassiana: Wald $=80.16$; $\mathrm{df}=4 ; p<0.001)$. With independent models where non-
Table 2 Median survival times (MST $\pm \mathrm{SE}$ ) of $A$. gambiae s.s. exposed to $M$. anisopliae ICIPE-30 and B. bassiana I93-825 when non-blood-fed and 3,12, 38, and $72 \mathrm{~h}$ since blood feeding

\begin{tabular}{lrrrr}
\hline $\begin{array}{l}\text { Fungus } \\
\text { species }\end{array}$ & $\begin{array}{l}\text { Blood-feeding status } \\
\text { before exposure } \\
\text { (no. of hours) }\end{array}$ & MST \pm SE (days) & $P$ value \\
\cline { 3 - 4 } & Control & Treatment n & \\
\hline $\begin{array}{l}\text { M. anisopliae } \\
\text { ICIPE-30 }\end{array}$ & Unfed & $14 \pm 0.56$ & $7 \pm 0.41$ & $<0.001$ \\
& 3 & $14 \pm 0.70$ & $7 \pm 0.46$ & $<0.001$ \\
& 12 & $18 \pm 0.06$ & $9 \pm 0.50$ & $<0.001$ \\
& 36 & $18 \pm 0.76$ & $9 \pm 0.46$ & $<0.001$ \\
B. bassiana & 72 & $16 \pm 0.81$ & $9 \pm 0.70$ & $<0.001$ \\
I93-825 & Unfed & $14 \pm 0.56$ & $7 \pm 0.22$ & $<0.001$ \\
& 3 & $14 \pm 0.70$ & $8 \pm 0.41$ & $<0.001$ \\
& 12 & $18 \pm 0.06$ & $10 \pm 0.57$ & $<0.001$ \\
& 36 & $18 \pm 0.76$ & $10 \pm 0.46$ & $<0.001$ \\
& 72 & $16 \pm 0.81$ & $10 \pm 0.32$ & $<0.001$ \\
\hline
\end{tabular}

blood-fed mosquitoes were independently compared with blood-fed categories, there was an interaction between blood feeding and fungus-induced mortality except for mosquitoes exposed to $B$. bassiana $72 \mathrm{~h}$ since blood feeding ( $M$. anisopliae: Wald $=23.25-52.56 ; \mathrm{df}=1 ; p<0.001, B$. bassiana: Wald $=16.63-50.42 ; \mathrm{df}=1 ; p<0.001$ ).

\section{Discussion}

When mosquitoes were exposed to either M. anisopliae or $B$. bassiana their survival, in all bioassays, was significantly reduced relative to their control counter parts. This supports previous laboratory trials that have demonstrated the potential of entomopathogenic fungi for adult mosquito control (Scholte et al. 2005; Blanford et al. 2005; Farenhorst et al. 2008). Our bioassays investigated the interaction between the pathogen, and host age and blood-feeding status, which are key factors affecting initiation and development of fungal infection (Dimbi et al. 2003).

Although older mosquitoes died relatively earlier than younger individuals, age did not affect mosquito susceptibility to fungal infection. Increased risk of death in older than younger individuals has also been reported elsewhere (Harrington et al. 2001; Styer et al. 2007). Finally, no interaction between age and fungus-induced mortality has been reported in housefly Musca domestica, onion fly Delia antiqua, and blackfly Phormia regina exposed to $M$. anisopliae and B. bassiana (Rizzo 1977). Contrarily, agedependent fungus-induced mortality has been observed, for example, in scarabeid larvae (Ferron 1967), Heliothis zea larvae (Mohamed et al. 1977), and adult tsetse flies (Maniania and Odulaja 1998). In these three cases, the fungus-induced mortality was relatively higher in older than younger individuals. Fungus-induced mortality, however, 
has been shown to decrease with age in noctuid larvae (Getsin 1961; Fargues and Rodriguez-Rueda 1980; Boucias et al. 1984).

Increased mortality rate among older individuals could be explained by various physiological properties that change with the age of mosquitoes and possibly other insect species. Older mosquitoes show reduced immune function. Melanization responses in laboratory reared $A$. gambiae declined within a short period of time (Chun et al. 1995; Schwartz and Koella 2002), and older individuals were only able to mount strong immune response after they were supplemented with blood (Schwartz and Koella 2002). Enzymes such as phenol oxidases, which are suggested to be important for melanization and sclerotization in the hemolymph (Chun et al. 1995), and numbers of immune competent hemocytes ( $\mathrm{Li}$ et al. 1992) decrease with age. A change in the number and morphology of circulating hemocytes was attributed to increased mortality in older Aedes aegypti (Hillyer et al. 2005). Moreover, glycogen and total soluble proteins deteriorate (Nayar and Sauerman 1973; Mourya et al. 1993) with age.

Non-blood-fed mosquitoes were more susceptible to fungus infection than blood-fed ones. A digested blood meal increases the nutrient reserve of the host, thus more time may be required for the fungus to deplete nutrients and kill the insect. In addition, insects with a digested blood meal can also mount a stronger immune response. This could have been the reason for the lower mortality in bloodfed relative to unfed mosquitoes, especially considering that histopathological studies of tissues infected by fungus suggest that the insect dies due to the combination of nutrient depletion, mechanical damage, and toxicosis (Ferron 1981; Gillespie and Claydon 1989). The fact that blood-fed mosquitoes are less susceptible to fungal infection could be beneficial in terms of evolution proofing against resistance development. Although fungal infection reduces the fecundity of female mosquitoes (Scholte et al. 2006), they are still able to pass their genes to the subsequent generation reducing selection pressure on resistance against fungi (Thomas and Read 2007). Furthermore, fungal infections suppress the successful development of Plasmodium parasites in the vectors (Blanford et al. 2005), and hence both effects (i.e., fungus-induced mortality and parasite resistance) lead to a significantly reduced parasite transmission risk.

\section{Conclusions}

Formulations of M. anisopliae and B. bassiana can equally infect mosquitoes of different age classes, more so when non-blood-fed. Therefore, delivery techniques that target host-seeking or house entering mosquitoes may be more effective than techniques targeting resting (and often bloodfed) mosquitoes. To expect more in terms of reducing wild mosquito populations, however, more efforts should gear towards producing more virulent and persistent fungal products.

Acknowledgements We are grateful to the Adessium foundation (Reeuwijk, The Netherlands) for funding this research.

Competing interests Authors declare that they have no competing interests.

Open Access This article is distributed under the terms of the Creative Commons Attribution Noncommercial License which permits any noncommercial use, distribution, and reproduction in any medium, provided the original author(s) and source are credited.

\section{References}

Beckett EB (1990) Development and ageing of the salivary glands of adult female Aedes aegypti (L.) and Aedes togoi (Theobald) mosquitoes (Diptera: Culicidae). J Insect Morphol Embryol 19:277-290

Blanford S, Chan BHK, Jenkins N, Sim D, Turner RJ, Read AF, Thomas MB (2005) Fungal pathogen reduces potential for malaria transmission. Science 308:1638-1641

Boucias DC, Bradford DL, Barfield CS (1984) Susceptibility of the velvet bean caterpillar and soybean looper (Lepidoptera: Noctuidae) to Nomuraea rileyi: effects of pathotype, dosage, temperature, and host age. J Econ Entomol 77:247-253

Brei B, Edman JD, Gerade B, Clark JM (2004) Relative abundance of two cuticular hydrocarbons indicates whether a mosquito is old enough to transmit malaria parasites. J Med Entomol 41:807-809

Chen CS, Mulla MS, March RB, Chaney JD (1990) Cuticular hydrocarbon patterns in Culex quinquefasciatus as influenced by age, sex, and geography. Bull Soc Vector Ecol 15:129-139

Chun J, Riehle M, Paskewitz SM (1995) Effect of mosquito age and reproductive status on melanization of sephadex beads in Plasmodium-refractory and -susceptible strains of Anopheles gambiae. J Invertebr Pathol 66:11-17

Dimbi S, Maniania NK, Lux SA, Mueke JM (2003) Host species, age and sex as factors affecting the susceptibility of the African tephritid fruit fly species, Ceratitis capitata, C. cosyra and $C$. fasciventris to infection by Metarhizium anisopliae. J Pest Sci 76:113-117

Farenhorst M, Farina D, Scholte EJ, Takken W, Hunt RH, Coetzee M, Knols BGJ (2008) African water storage pots for the delivery of the entomopathogenic fungus Metarhizium anisopliae to the malaria vectors Anopheles gambiae s.s. and Anopheles funestus. Am J Trop Med Hyg 78:910-916

Farenhorst M, Mouatcho JC, Kikankie CK, Brooke BD, Hunt RH, Thomas MB, Koekemoer LL, Knols BGJ, Coetzee M (2009) Fungal infection counters insecticide resistance in African malaria mosquitoes. Proc Natl Acad Sci USA 106:17443-17447

Fargues J, Rodriguez-Rueda D (1980) Sensibilité des larves de Spodoptera littoralis (Lep.: Noctuidae) aux hyphomycètes entomopathogènes Nomuraea rileyi et Paecilomyces fumosoroseus. Entomophaga 25:43-54

Feder D, Mello CB, Garcia ES, Azambuja P (1997) Immune responses in Rhodnius prolixus: influence of nutrition and ecdysone. J Insect Physiol 43:513-519 
Feng Z, Carruthers RI, Roberts DW, Robson DS (1985) Age-specific dose-mortality effects of Beauveria bassiana on the European corn borer, Ostrinia nubilalis. J Invertebr Pathol 46:259-264

Ferron P (1967) Essais préliminaires de la lutte contre les larves du hanneton commun, Melolontha melolontha L. à l'aide de la mycose a Beauveria tenella (Delacr.) Siemaszko. PhytiatriePhytopharmacie 16:115-123

Ferron P (1981) Pest control by the fungi Beauveria and Metarhizium. In: Microbial control of pests and plant diseases 1970-1980. Academic, London

Ffrench-Constant RH (2005) Something old, something transgenic, or something fungal for mosquito control? Trends Ecol Evol 20:577-579

Getsin LW (1961) Spicaria rileyi (Farlow) Charles, an entomogenous fungus of Trichoplusiani (Hubner). J Invertebr Pathol 3:2-10

Gillespie AT, Claydon N (1989) The use of entomogenous fungi for pest control and the role of toxins in pathogenesis. Pest Sci 27:203-215

Gillies MT, Wilkes TJ (1965) A study of the age-composition of populations of Anopheles gambiae Giles and A. funestus Giles in North-Eastern Tanzania. Bull Entomol Res 56:237-262

Hancock PA (2009) Combining fungal biopesticides and insecticidetreated bednets to enhance malaria control. PLoS Comput Biol 5: e 1000525

Harrington LC, Buonaccorsi JP, Edman JD, Costero A, Kittayapong P, Clark GG, Scott TW (2001) Analysis of survival of young and old Aedes aegypti (Diptera: Culicidae) from Puerto Rico and Thailand. J Med Entomol 38:537-547

Hillyer JF, Schmidt SL, Fuchs JF, Boyle JP, Christensen BM (2005) Age-associated mortality in immune challenged mosquitoes (Aedes aegypti) correlates with a decrease in haemocyte numbers. Cell Microbiol 7:39-51

Hodjati MH, Curtis CF (1999) Evaluation of the effect of mosquito age and prior exposure to insecticide on pyrethroid tolerance in Anopheles mosquitoes (Diptera: Culicidae). Bull Entomol Res 89:329-337

Hugo LE, Kay BH, Eaglesham GK, Holling N, Ryan PA (2006) Investigation of cuticular hydrocarbons for determining the age and survivorship of Australasian mosquitoes. Am J Trop Med Hyg 74:462-474

Huho BJ, Ng'habi KR, Killeen GF, Nkwengulila G, Knols BGJ, Ferguson HM (2007) Nature beats nurture: a cast study of the physiological fitness of free-living and laboratory-reared male Anopheles gambiae s.1. J Exp Biol 210:2939-2947

Koella JC, Lynch PA, Thomas MB, Read AF (2009) Towards evolutionproof malaria control with insecticides. Evol Appl 2:469-480

Li J, Tracy JW, Christensen BM (1992) Relationship of hemolymph phenol oxidase and mosquito age in Aedes aegypti. J Invertebr Pathol 60:188-191

Maniania NK, Odulaja A (1998) Effect of species, age and sex of tsetse on response to infection by Metarhizium anisopliae. Biocontrol 43:311-383

Mnyone LL, Kirby MJ, Lwetoijera DW, Mpingwa MW, Knols BGJ, Takken W, Russell TL (2009) Infection of the malaria mosquito,
Anopheles gambiae with two species of entomopathogenic fungi: effects of concentration, co-formulation, exposure time and persistence. Malar J 8:309

Mohamed AKA, Sikorowski P, Bell JV (1977) The susceptibility of Heliothis zea larvae to Nomuraea rileyi at various temperatures. J Invertebr Pathol 12:444-459

Mourya DT, Hemingway J, Leake CJ (1993) Changes in enzyme titres with age in four geographical strains of Aedes aegypti and their association with insecticide resistance. Med Vet Entomol 7:11-16

Mullens BA (1985) Host, age and sex and pathogen exposure levels as factors in the susceptibility of Musca domestica to Entomophthora muscae. Ent Exp Appl 37:330-339

Nayar JK, Sauerman DM Jr (1973) A comparative study of flight performance and fuel utilization as a function of age in females of Florida mosquitoes. J Insect Physiol 19:1977-1988

Okech BA, Gouagna LC, Killeen GF, Knols BG, Kabiru EW, Beier JC, Yan G, Githure JI (2003) Influence of sugar availability and indoor microclimate on survival of Anopheles gambiae (Diptera: Culicidae) under semifield conditions in western Kenya. J Med Entomol 40:657-663

Read AF, Lynch PA, Thomas MB (2009) How to make evolutionproof insecticides for malaria malaria control. PLoS Biol 7: e1000058

Rizzo DC (1977) Age of three dipteran hosts as a factor governing the pathogenicity of Beauveria bassiana and Metarhizium anisopliae. J Invertebr Pathol 30:127-130

Rowley WA, Graham CL (1968) The effect of age on the flight performance of female Aedes aegypti mosquitos. J Insect Physiol 14:719-728

Scholte EJ, Ng'habi K, Kihonda J, Takken W, Paaijmans K, Abdulla S, Killeen GF, Knols BGJ (2005) An entomopathogenic fungus for control of adult African malaria mosquitoes. Science 308:1641-1642

Scholte EJ, Knols BG, Takken W (2006) Infection of the malaria mosquito Anopheles gambiae with the entomopathogenic fungus Metarhizium anisopliae reduces blood feeding and fecundity. J Invertebr Pathol 91:43-49

Schwartz A, Koella JC (2002) Melanization of Plasmodium falciparum and C-25 sephadex beads by field-caught Anopheles gambiae (Diptera: Culicidae) from southern Tanzania. J Med Entomol 39:84-88

Scott TW, Chow E, Strickman D, Kittayapong P, Wirtz RA, Lorenz LH, Edman JD (1993) Blood-feeding patterns of Aedes aegypti (Diptera: Culicidae) collected in a rural Thai village. J Med Entomol 30:922-927

Scott TW, Naksathit A, Day JF, Kittayapong P, Edman JD (1997) A fitness advantage for Aedes aegypti and the viruses it transmits when females feed only on human blood. Am J Trop Med Hyg 57:235-239

Styer LM, Carey JR, Wang JL, Scott TW (2007) Mosquitoes do senesce: departure from the paradigm of constant mortality. Am J Trop Med Hyg 76:111-117

Thomas MB, Read AF (2007) Can fungal biopesticides control malaria? Nat Rev Microbiol 5:377-383 